\title{
A CHAVE DA INOVAÇÃO
}

A inovação em países emergentes nunca esteve tão em voga. Países em desenvolvimento têm obtido investimentos recordes visando à promoção da inovação, chave para a competitividade de organizações e para o desenvolvimento econômico e social. Os títulos selecionados nestas indicações ajudam a compreender o papel da inovação em setores industriais e no que tange ao aumento da competitividade dos países emergen- tes. Glauco Arbix é Professor do Departamento de Sociologia da Universidade de São Paulo (USP), Coordenador Geral do Observatório da Inovação e Competitividade do Instituto de Estudos Avançados (USP) e presidente sa Financiadora de Estudos e Projetos (Finep). Rafael Grilli Felizardo é mestrando do Departamento de Sociologia da USP e pesquisador do Observatório da Inovação e Competitividade.

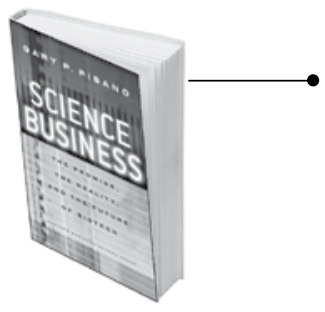

SCIENCE BUSINESS: The promise, the reality and the future of biotech. Gary P. Pisano. Boston: Harvard Business School Press Book, 2006. 256 p.

Gary P. Pisano é Professor de Harvard e um dos maiores especialistas contemporâneos em biotecnologia. Não é um cientista de laboratório, mas daqueles que pensam como os pesquisadores devem funcionar na intersecção entre o mundo acadêmico e as empresas. Foi um dos pioneiros a identificar como a indústria da biotecnologia precisa da pesquisa básica para mostrar-se operacional e inserida no mercado. Trata-se, para ele, de um negócio que só pode funcionar se estiver baseado na pesquisa científica de fronteira. O livro é imprescindível para empresários, pesquisadores, investidores e formuladores de políticas para o setor de biotecnologia.

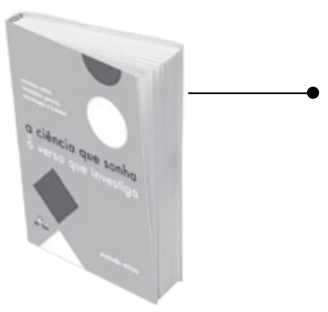

A CIÊNCIA QUE SONHA E O VERSO QUE INVESTIGA: Ensaios sobre inovação, poesia, tecnologia e futebol. Evando Mirra. São Paulo: Papagaio e Observatório da Inovação e Competitividade (USP), 2009. 353 p.

O livro de Evando Mirra é de fino trato. Aborda com linguagem literária temas difíceis como os relacionados à tecnologia e inovação, sem perder a precisão que todo bom engenheiro, como o autor, gosta de ter. O livro é fruto de uma vida dedicada a estabelecer conexões entre instituições, processos e temas aparentemente distantes, como os fios invisíveis que ligam a ciência e tecnologia ao futebol e ao jazz. Nas palavras do autor - que foi presidente do Conselho Nacional de Desenvolvimento Científico e Tecnológico ( $\mathrm{CNPq}$ ) e vice-reitor da Universidade Federal de Minas Gerais - a ciência coexiste e coevolui com a poesia e as artes em geral. A obra faz parte de uma coleção dedicada às experiências inovadoras na indústria e serviços.

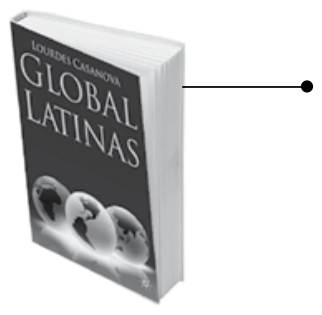

GLOBAL LATINAS: Latin America`s emerging multinationals. Lourdes Casanova. New York: Insead Business Press-Palgrave Macmillan, 2009. 200 p.

O dinamismo das multinacionais latino-americanas é tratado extensivamente neste livro de Lourdes Casanova. Empresas como Petrobras, Cemex, Vale, Tenaris, América Móvil, Politec, Natura, Bimbo, Embraer e Concha y Toro são tratadas como frutos inesperados de um continente que poucos imaginaram poderia dar-se ao luxo de possuir multinacionais. As empresas, desafiando teorias, expandiram-se e, tudo indica, chegaram para ficar. Sua internacionalização é agressiva, em especial após a liberalização das economias levada a cabo nos anos 1990. Se há sinais que sugerem uma inflexão da economia mundial para a Ásia, em especial por conta da China e da Índia, as novas multilatinas funcionam como um contraponto de peso. Pedem, por isso mesmo, atenção especial de pesquisadores, analistas e governantes, pois a legislação, incentivos e apoio estão longe de serem apropriados.

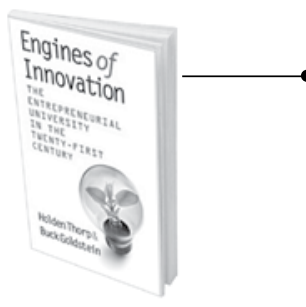

ENGINES OF INNOVATION: The entrepreneurial university in the twenty-first century. Holden Thorp e Buck Goldstein. North Carolina: The University of North Caroline Press, 2010. 192 p.

Inovação é tema crucial para países em desenvolvimento como o Brasil. Raros são os analistas que deixam de apontar a inovação como prioridade número um para governos e empresas. Mas, quando o assunto bate à porta das universidades (centros de geração de conhecimento e formação de gente qualificada), nem sempre o debate flui livremente e de modo produtivo. O resultado é que parte significativa da comunidade acadêmica às vezes não consegue enxergar com clareza seu lugar e importância nos processos inovadores. No mundo todo, após a docência e a pesquisa, o sistema universitário está sendo convidado, quando não pressionado, a assumir um lugar especial na intersecção entre a produção de conhecimento de fronteira e a sintonia com os esforços pelo desenvolvimento de povos e países. As questões colocadas pelos autores derrubam mitos, estantes e muros que cercam a universidade e mostram como o assunto deve ser enfrentado pelas sociedades. 